Article

\title{
Photocatalytic Removal of Methyl Orange Azo Dye with Simultaneous Hydrogen Production Using Ru-Modified ZnO Photocatalyst
}

\author{
Vincenzo Vaiano and Giuseppina Iervolino * \\ Department of Industrial Engineering, University of Salerno, Via Giovanni Paolo II, 132, 84084 Fisciano, Salerno, \\ Italy; vvaiano@unisa.it \\ * Correspondence: giiervolino@unisa.it
}

Received: 21 October 2019; Accepted: 13 November 2019; Published: 15 November 2019

\begin{abstract}
The aim of this work is to demonstrate the effectiveness of the photocatalytic process in the Methyl Orange azo dye degradation and simultaneous $\mathrm{H}_{2}$ production by using $\mathrm{ZnO}$ doped with ruthenium. Ru-modified $\mathrm{ZnO}$ photocatalysts were prepared by precipitation method and were characterized by different techniques (XRF, Raman, XRD, N2 adsorption at $-196^{\circ} \mathrm{C}$, and UV-vis DRS). The experiments were carried out in a pyrex cylindrical reactor equipped with a nitrogen distributor device and irradiated by four UV lamps with the main wavelength emission at $365 \mathrm{~nm}$. Different Ru amounts (from 0.10 to $0.50 \mathrm{~mol} \%$ ) were tested in order to establish the optimal amount of the metal to be used for the $\mathrm{ZnO}$ doping. The photocatalytic activity was evaluated both in terms of Methyl Orange removal and hydrogen production. The experimental results showed that the best activity, both in terms of $\mathrm{H}_{2}$ production and Methyl Orange degradation, was obtained with the Ru-modified $\mathrm{ZnO}$ photocatalyst at $0.25 \mathrm{~mol} \% \mathrm{Ru}$ loading. In particular, after four hours of UV irradiation time, the discoloration and mineralization degree were equal to $83 \%$ and $78 \%$, with a simultaneous hydrogen production of $1216 \mu \mathrm{mol} \mathrm{L}^{-1}$. This result demonstrates the ability of the photocatalytic process to valorize a dye present in wastewater, managing to obtain a hydrogen production comparable with the data present in the literature today in the presence of other sacrificial substances.
\end{abstract}

Keywords: photocatalysis; zinc oxide; azo dye; hydrogen production; textile wastewater

\section{Introduction}

Renewable energies represent the future of our planet. Oil, coal, methane and natural fossil fuels formed during the evolution of the Earth, to date, meet more than $80 \%$ of the world's energy needs. However, in relatively short timeframes these resources will come very close to exhaustion. Therefore, scientific research has begun to pay close attention to the efficiency of industrial processes and the minimization of waste, especially in the energy sector. $\mathrm{H}_{2}$ could be a promising choice for a future energy resource because it is free of pollution, storable, and highly demanded by fuel cell industries. Different technologies have been proposed for its production and photocatalysis represents an innovative technology with wide margins of development. Hydrogen produced via photocatalytic water splitting has been considered as a promising alternative technology [1]. However, the introduction of "sacrificial agents", such as ethanol, methanol, and glucose promotes the photocatalytic hydrogen production [2,3]. The addition of these organic compounds can improve the photocatalytic $\mathrm{H}_{2}$ production efficiency by consuming the photo-induced hole for better electron-hole separation. At the same time, the concern of the industry is the disposal and treatment of wastewater. In particular, in industrial wastewater, there are many persistent contaminants that can damage the environment and the health of living beings. An interesting approach is to explore the possibility of producing an 
energy source, such as hydrogen, in parallel to wastewater treatment, from the degradation of organic substances present in wastewater through the photocatalytic application [4]. In fact, if the sacrificial agent is a pollutant present in water or wastewater, the overall process would enhance the $\mathrm{H}_{2}$ production rate while simultaneously degrading the organic substrate [5]. Nowadays, much attention has been paid to the huge amount of dye-containing wastewater generated by the textile industry. The presence of coloured effluents causes both a negative aesthetic impact, but also serious environmental pollution. Organic dyes are one of the most serious water pollutants, due to their high production volumes from industry, toxicity, and low biodegradability [6]. It has been estimated that the annual production of organic dyes amounts to approximately one million tons and a significant amount (about 10-15\%) of wastewater containing dyes is discharged to the surface water without any treatment [7]. Some organic dyes are carcinogenic to humans and negatively affect aquatic organisms by interfering with their metabolic processes [8]. Textile dyes with complex structures are highly resistant to conventional physicochemical and biological degradation. In order to obtain the removal of these kinds of pollutants, advanced oxidation processes have been studied. Much progress has been made in the field of photocatalytic processes for the removal of textile dyes [9-12]. Therefore, it could be interesting to exploit the capabilities of photocatalysis to convert this type of organic pollutant into compounds with high added value. In literature, the use of bifunctional $\mathrm{TiO}_{2}$ photocatalysts, achieved through the surface modification of $\mathrm{TiO}_{2}$ with metal nanoparticles or two different components, has been proposed for simultaneous hydrogen production and pollutant degradation (urea) in the presence of UV light [13]. Titania is one of the most widely used semiconductors in heterogeneous photocatalysis, both for the removal of pollutants from wastewater [14], and for hydrogen production via water splitting (Miyoshi et al., 2018) or reforming of organic substances [15]. An aqueous solution containing an azo dye, Acid Orange 7 (initial concentration: $12 \mathrm{mg} / \mathrm{L}$ ), and a $\mathrm{Pt} / \mathrm{TiO}_{2}$ photocatalyst irradiated by UV light, was used to combine into a single process the dye degradation and hydrogen production [5]. In this paper, a photocatalytic hydrogen production equal to about $4000 \mu \mathrm{mol} / \mathrm{L}$, after 8 hours of irradiation, was observed [5]. In literature, the simultaneous production of molecular hydrogen and degradation of rhodamine $\mathrm{B}(\mathrm{RhB})$ was reported [6]. In this case, $\mathrm{TiO}_{2}$ modified with platinum and nafion $\left(\mathrm{Pt} / \mathrm{TiO}_{2} / \mathrm{Nf}\right)$ under visible light $(\lambda>420 \mathrm{~nm})$ was used. This photocatalyst exhibited high activity for $\mathrm{H}_{2}$ production in the presence of an RhB dye pollutant and ethylenediaminetetraacetic acid (EDTA), which act as a photosensitizer and an electron donor, respectively. With an initial concentration of RhB equal to $10 \mathrm{mg} / \mathrm{L}$ and EDTA equal to $4 \mathrm{mM}$, approximately $2300 \mu \mathrm{mol} / \mathrm{L}$ of $\mathrm{H}_{2}$ was produced after 14 hours of visible light irradiation [6]. In another paper, photocatalytic hydrogen production was performed by a visible-light-driven ternary photocatalyst, zinc oxysulfide $\left(\mathrm{ZnO}_{0.6} \mathrm{~S}_{0.4}\right)$, in the presence of a sulfide/sulfite $\left(\mathrm{S}_{2}{ }^{2-} / \mathrm{SO}_{3}{ }^{2-}\right)$ sacrificing system, with simultaneous azo-dye Reactive Violet 5 (RV5) degradation [16]. Results of other studies using different photocatalysts and dye pollutants are listed in Table 1.

Table 1. Comparison of hydrogen production from the data of other literature with different photocatalysts.

\begin{tabular}{|c|c|c|c|c|}
\hline $\begin{array}{l}\text { Photocatalyst } \\
\text { (Co-Catalyst) }\end{array}$ & Sacrificing Agent & Light Source * & $\begin{array}{c}\mathrm{H}_{2} \text { Production Rate } \\
\left(\mu \mathrm{mol} \mathrm{g}^{-1} \mathrm{~h}^{-1}\right)\end{array}$ & Reference \\
\hline $\mathrm{ZnO0.6S0.4}$ & Sulfide/sulfite + RV5 & Vis & 49.2 & [16] \\
\hline $\mathrm{Ti}^{3+}$-doped $\mathrm{TiO}_{2}(1 \% \mathrm{Pt})$ & Methylene Blue & Vis & $\sim 14$ & [17] \\
\hline $\mathrm{Ti}^{3+}$-doped $\mathrm{TiO}_{2}(1 \% \mathrm{Pt})$ & Rhodamine B & Vis & $\sim 8.3$ & [17] \\
\hline $\mathrm{Ti}^{3+}$-doped $\mathrm{TiO}_{2}(1 \% \mathrm{Pt})$ & Methyl Orange & Vis & $\sim 5$ & [17] \\
\hline $\mathrm{TiO}_{2}(0.5 \% \mathrm{Pt})$ & Methanol + Methyl Orange & UV-vis & $\sim 420$ & [18] \\
\hline Simonkolleite- $\mathrm{TiO}_{2}$ & Remazole Red & UV-vis & $\sim 825$ & [19] \\
\hline $\mathrm{TiO}_{2}(0.5 \% \mathrm{Pt})$ & Acid Orange 7 & UV-vis & $\sim 450$ & [5] \\
\hline $\mathrm{Pt} / \mathrm{TiO}_{2} / \mathrm{Nf}$ & RhB dye pollutant + EDTA & UV & $\sim 380$ & {$[6]$} \\
\hline
\end{tabular}

It is not easy to compare the data from different literature because the experimental conditions are different, such as the photocatalyst dosage, the type of dye, the presence of co-catalysts, the light source, and so on. However, it is interesting to collect literature data on this topic to understand the 
interest of the scientific community and the developments. As observed in Table 1, the most commonly used photocatalyst in this field is $\mathrm{TiO}_{2}$. However, in addition to $\mathrm{TiO}_{2}$, several semiconductors, such as $\mathrm{ZnO}$ [20] and $\mathrm{LaFeO}_{3}$ [21] have been proposed in the literature, whose performances seem to be competitive compared to those of $\mathrm{TiO}_{2}$. Among these photocatalysts, it is well known that $\mathrm{ZnO}$ is an environment-friendly semiconductor with a bandgap of $3.37 \mathrm{eV}$. However, the quick recombination of the photoexcited electrons and holes in $\mathrm{ZnO}$ always leads to a decline in the photocatalytic efficiency [22]. It is possible to solve this problem by applying modifications to the electronic structure of the catalyst, for example by modifying the surface of the semiconductor with the addition of other elements, such as metals, metal oxides, or through a synergistic effect in combination with another semiconductor. In this way, it is possible to improve the efficiency of the photocatalyst in these reactions [23]. Besides noble metals, transition metals can also be used to dope the semiconductors, improving the trapping of electrons and inhibiting the electron-hole recombination. In particular, ruthenium, a transition metal, is much cheaper than noble metals (about eight times less expensive than rhodium;) but it is shown to be able to improve the photocatalytic efficiency of the semiconducting materials in the same way. For example, the performances of $\mathrm{Ru} / \mathrm{CeO}_{2}$ catalysts in the catalytic wet air oxidation of acrylic, succinic acids have been reported [24]. Aranganayagam et al. showed the photocatalytic activity of Ru-modified $\mathrm{ZnO}$ for the removal of an azo dye in an aqueous solution [25]. From the photocatalytic results the authors evidenced that Ru-modified $\mathrm{ZnO}$ has a photocatalytic property better than pure $\mathrm{ZnO}$. Therefore, considering the performance of the $\mathrm{ZnO}$ photocatalyst and the properties of the transition metals effective for the semiconductor modifications, the aim of this work was to demonstrate the effectiveness of a Ru-modified $\mathrm{ZnO}$ photocatalyst for the degradation of a textile azo dye, Methyl Orange (MO), with the simultaneous $\mathrm{H}_{2}$ production under UV irradiation.

\section{Results and Discussion}

\subsection{Characterizations and Results}

The XRD results of the undoped and Ru-modified $\mathrm{ZnO}$, with different Ru contents, are reported in Figure 1. From the spectra, in the range $20-80^{\circ}$, it is possible to observe the main peaks at $31.90^{\circ}, 34.58^{\circ}$, $36.43^{\circ}, 47.08^{\circ}$, and $56.72^{\circ}$, typical of the hexagonal wurtzite crystal structure, respectively indexed to

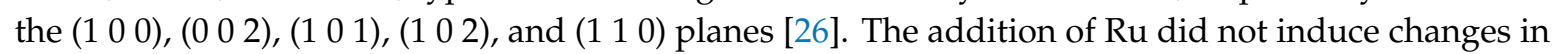
the crystalline structure of $\mathrm{ZnO}$. This last result is consistent with the literature concerning Ru-modified $\mathrm{ZnO}$ [27]. In addition, no signals related to metallic $\mathrm{Ru}$ or ruthenium oxides were observed for 0.1 and $0.25 \mathrm{Ru} \mathrm{mol} \%$. On the other hand, as doping percentage of Ru was increased up to $0.5 \mathrm{~mol} \%$, a very weak signal at about $39^{\circ}$ corresponding to $\mathrm{RuO}_{2}$ appeared [28].

The average crystallite size (calculated using the Scherrer equation [29]) of the bare $\mathrm{ZnO}$ was $35 \mathrm{~nm}$ (Table 2). With an increase of the Ru amount up to $0.25 \mathrm{~mol} \%$, the crystallite size decreased to $32 \mathrm{~nm}$, but when the Ru content was further increased to $0.5 \mathrm{~mol} \%$, the value of crystallite size slightly increased, being equal to $33 \mathrm{~nm}$ (Table 2). Accordingly, the highest SSA value was observed for the $0.25 \mathrm{Ru}$ photocatalyst (Table 2).

The results of Raman analysis in the range of $200-700 \mathrm{~cm}^{-1}$ of the all prepared catalysts are shown in Figure 2. The main band at $438 \mathrm{~cm}^{-1}$ corresponds to the non-polar optical phonons $\mathrm{E}_{2}$ (high) mode of $\mathrm{ZnO}$ [30]. At $583 \mathrm{~cm}^{-1}$ Raman shift there is the signal probably attributed to the longitudinal optical phonon (LO) feature, due to the formation of defects such as oxygen vacancy, as reported in the literature [31]. 


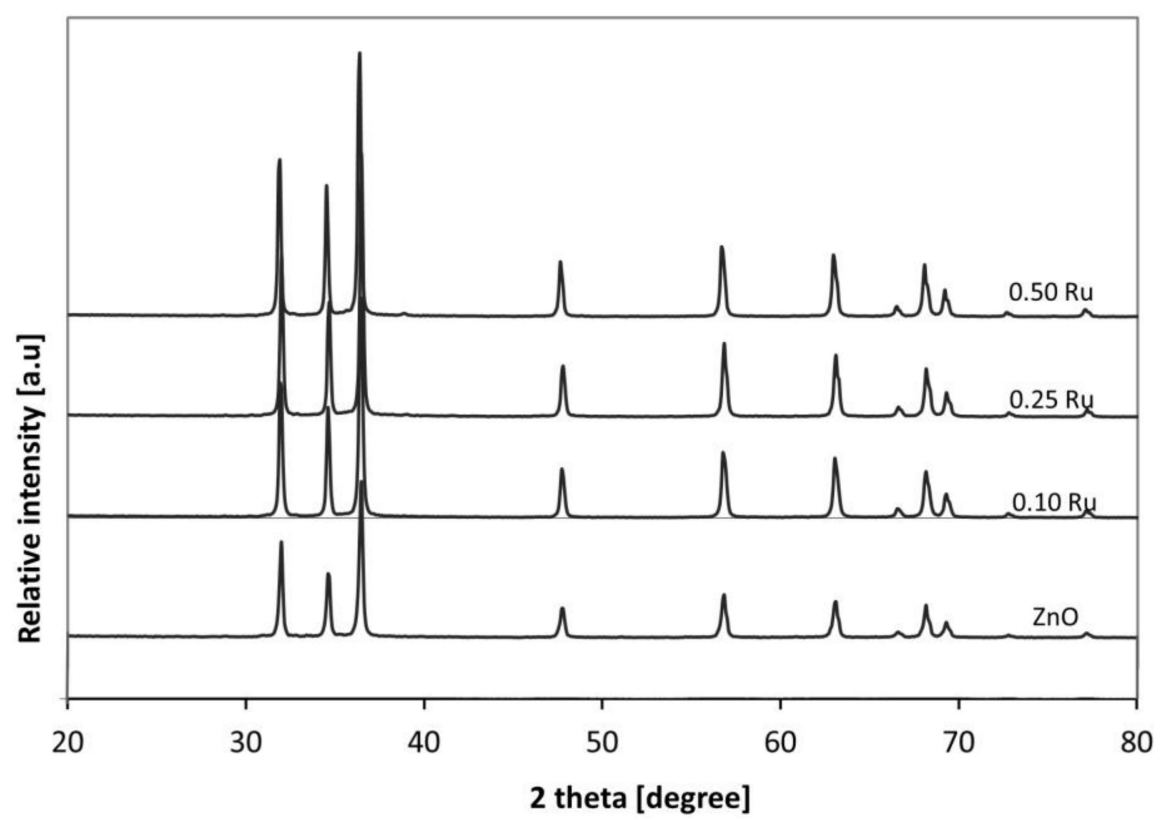

Figure 1. XRD spectra of undoped $\mathrm{ZnO}$ and $\mathrm{Ru}$-modified $\mathrm{ZnO}$ photocatalysts in the range $20-80^{\circ}$.

Table 2. The chemical-physical characteristics of the prepared photocatalysts.

\begin{tabular}{cccccc}
\hline Photocatalyst & $\begin{array}{c}\text { Ru Nominal } \\
\text { Amount }[\% \text { mol] }\end{array}$ & $\begin{array}{c}\text { Ru Measured } \\
\text { Amount }[\% \text { mol] }\end{array}$ & $\begin{array}{c}\text { Band Gap } \\
\text { Energy }{ }^{* *}[\mathrm{eV}]\end{array}$ & $\begin{array}{c}\text { Crystallite } \\
\text { Size }[\mathrm{nm}]\end{array}$ & SSA $^{* *}\left[\mathbf{m}^{2} / \mathbf{g}\right]$ \\
\hline $\mathrm{ZnO}$ & 0 & 0 & 3.20 & 35 & 5.5 \\
$0.10 \mathrm{Ru}$ & 0.10 & 0.09 & 3.20 & 34 & 6.1 \\
$0.25 \mathrm{Ru}$ & 0.25 & 0.22 & 3.20 & 32 & 7.2 \\
$0.50 \mathrm{Ru}$ & 0.5 & 0.53 & 3.17 & 33 & 5.8 \\
\hline
\end{tabular}

* by XRF analysis; ${ }^{* *}$ by UV-vis diffuse reflectance spectroscopy (DRS), ${ }^{* * *}$ by Brunauer, Emmett and Teller method (B.E.T.).

It was observed that, as the Ru doping concentration was increased, the intensities of the spectra decreased and the LO feature signal tended to disappear [32]. Optical absorption properties of the catalysts were studied through UV-vis DRS in the range of 300-900 nm (Figure 3). The undoped zinc oxide presents the typical reflectance spectrum of UV active semiconducting materials, with the absorption onset at about $390 \mathrm{~nm}$. After the doping of the $\mathrm{ZnO}$ with $\mathrm{Ru}$, an improvement in the intensity of light absorption in the UV region was observed. All the Ru-modified $\mathrm{ZnO}$ samples evidenced a continuous absorption in the visible range and the absorption was stronger with the increase of $\mathrm{Ru}$ content [27]. This last result may be explained considering the fact that undoped $\mathrm{ZnO}$ appears as a white powder, while the modification with ruthenium turns the samples into dark green colour, which is more pronounced at a higher Ru concentration [33]. Some authors associate this phenomenon to the excitation of the electrons from the valance band of $\mathrm{ZnO}$ to the unoccupied level of the metal cluster [34]. However, the presence of the Ru doping did not affect the band gap energy value of the prepared photocatalysts. A slight decrease in the band gap value is obtained only in the case of the higher ruthenium molar percentage used for the doping $(0.50 \mathrm{~mol} \%)$. Thus, the beneficial effect of Ru may be related to its ability to act as an efficient electron trap, thereby preventing the electron-hole recombination. The results of the band gap energy are reported in Table 2. 


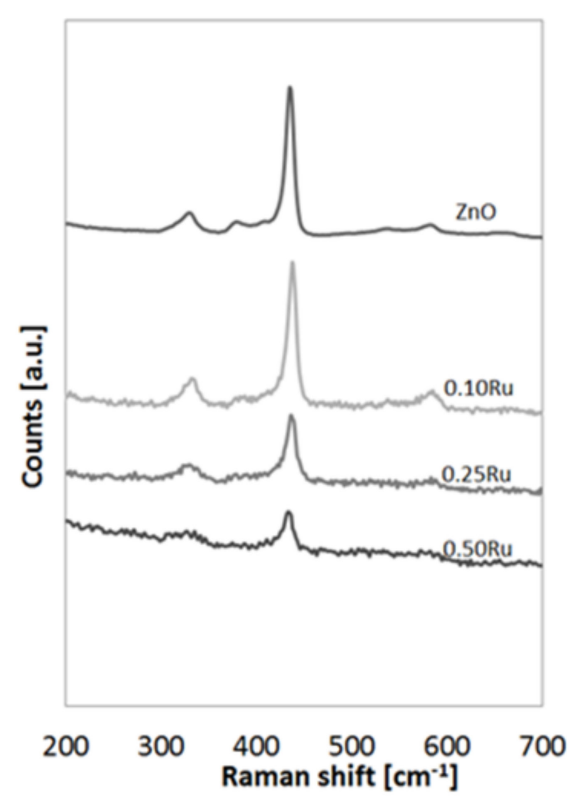

Figure 2. Raman spectra of the undoped and Ru-modified $\mathrm{ZnO}$ in the range $200-700 \mathrm{~cm}^{-1}$.

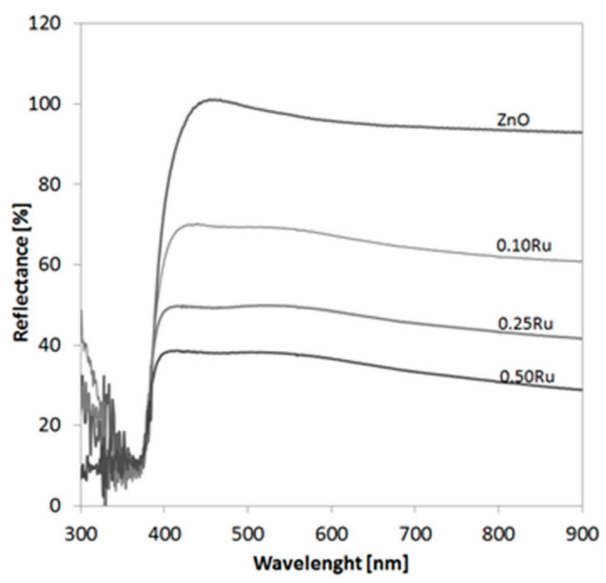

Figure 3. UV-Vis DRS spectra of undoped and Ru-modified ZnO photocatalyst in terms of reflectance as a function of wavelength.

\subsection{Photocatalytic Activity Results}

The effect of $\mathrm{Ru}$ content on photocatalytic $\mathrm{H}_{2}$ production and $\mathrm{MO}$ removal are reported in Figures 4 and 5a,b, respectively. All the Ru-modified $\mathrm{ZnO}$ photocatalysts demonstrated a photoactivity better than the undoped $\mathrm{ZnO}$. The greatest hydrogen production $\left(1216 \mu \mathrm{mol} \mathrm{L}{ }^{-1}\right)$ was achieved for the $0.25 \mathrm{Ru}$ catalyst after $4 \mathrm{~h}$ of UV irradiation time (Figure 4 ). The hydrogen production efficiency increased when Ru mol\% was increased from 0.10 to $0.25 \mathrm{~mol} \%$ and decreased when the Ru content was further increased up to $0.50 \mathrm{~mol} \%$, reaching a value equal to $983 \mu \mathrm{mol} \mathrm{L}^{-1}$ after $4 \mathrm{~h}$ of irradiation time. In terms of MO degradation, the results obtained with different Ru content showed very similar discoloration and mineralization values (about $82 \%$ and $78 \%$ of discoloration and mineralization at the end of the test, respectively) (Figure 5a,b). Aiming to obtain, simultaneously, the degradation of the azo dye and its valorization in terms of hydrogen production, the optimal catalyst must be considered the $0.25 \mathrm{Ru}$ sample. These results are very interesting if compared with the literature data [18]. 


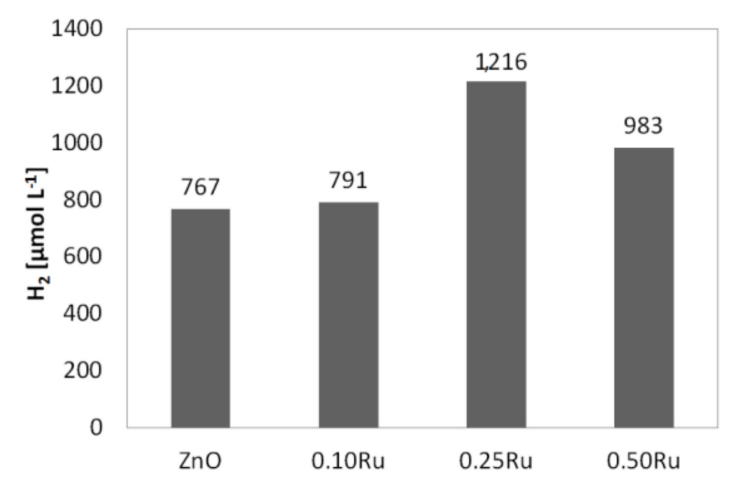

Figure 4. Effect of $\mathrm{Ru}$ content on $\mathrm{H}_{2}$ production after $4 \mathrm{~h}$ of $\mathrm{UV}$ irradiation time.
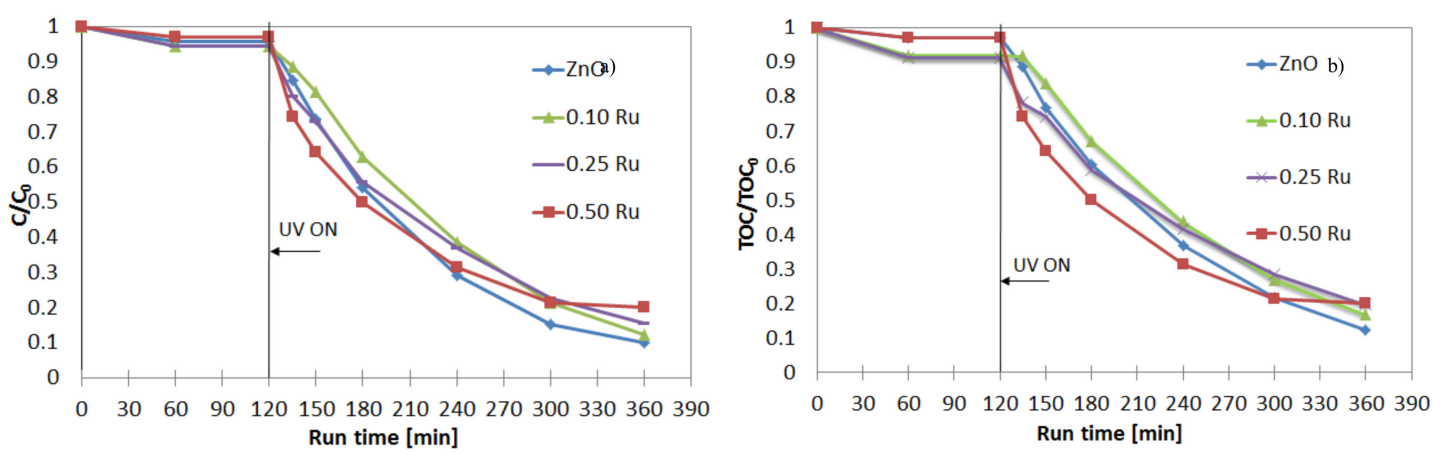

Figure 5. Effect of the Ru content on methyl orange (MO) discoloration (a) and mineralization (b) during the run time.

In literature, it has been reported that the photocatalytic hydrogen production from MO (at $20 \mathrm{mg} \mathrm{L}^{-1}$ initial concentration) degradation is improved by methanol addition $(2.5 \mathrm{M})$ and using a Pt based photocatalyst [18]. In this last case, the maximum hydrogen production was equal to about $9 \mu \mathrm{mol} \mathrm{g}^{-1}$ cat $\min ^{-1}$. In our case, the highest hydrogen production corresponds to about $1 \mu \mathrm{mol}$ $\mathrm{g}^{-1}$ cat $\min ^{-1}$. Although this production seems much lower than that found in the literature, it must be considered that, in our case, the hydrogen production was obtained in the absence of an additional sacrificial agent (methanol) and noble metals. Moreover, in the present study it is possible to assume that the MO degradation occurs thanks to the photogenerated oxygen from the water oxidation under UV irradiation. According to the literature [5], it is possible to argue that the photogenerated oxygen is consumed for the oxidation of the MO until its complete mineralization is obtained. The effect of catalyst dosage on the performances of the system after $4 \mathrm{~h}$ of UV irradiation was also evaluated (Figure 6). The photocatalytic efficiency increased as the catalyst loading was increased up to $1.5 \mathrm{~g} \mathrm{~L}^{-1}$. Further increase of catalyst load resulted in a decrease of hydrogen production (Figure 6). The presence of an optimal value for the catalyst loading is likely related to the limiting effect of the interception of the light by the catalyst particles on the degradation efficiency [35]. Moreover, from the experimental results, a correlation between the dye percentage adsorbed in dark conditions on the catalyst surface and the hydrogen production obtained during the UV irradiation has emerged. The exposed catalyst surface area decreases as the catalyst dosage increases due to aggregation phenomena of photocatalyst particles [36], worsening the amount of the adsorbed dye. This last parameter also influences the photocatalytic hydrogen production. In fact, the highest percentage of MO adsorbed (obtained with a catalyst dosage equal to $1.5 \mathrm{~g} \mathrm{~L}^{-1}$ ) corresponds to the highest hydrogen production (Figure 6). 


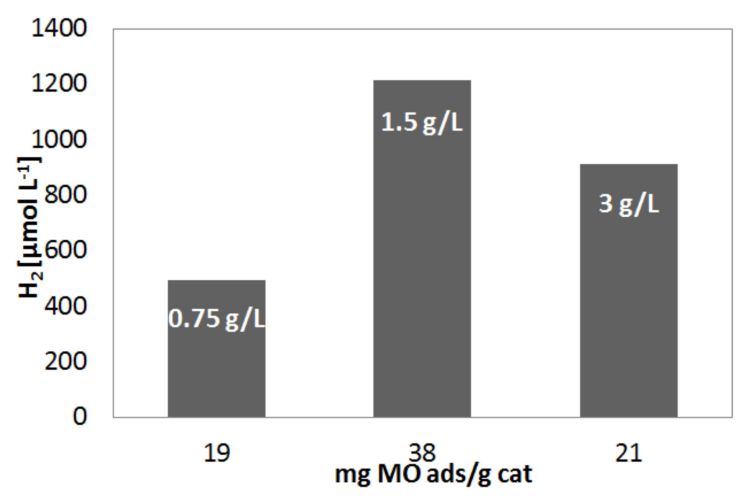

Figure 6. The effect of catalyst dosage on $\mathrm{H}_{2}$ production after $4 \mathrm{~h}$ of UV irradiation time.

Photocatalytic hydrogen production obtained following the addition of variable concentrations of $\mathrm{MO}$ (in the range $5-20 \mathrm{mg} \mathrm{L}^{-1}$ ) to the solution prior to exposure to light, at the spontaneous $\mathrm{pH}$, are summarized in Figure 7. The results evidence that an optimal initial concentration of dye exists and with this concentration the highest hydrogen production was obtained. This behaviour is in agreement with the literature about the photocatalytic hydrogen production from azo dyes in an aqueous solution [5].

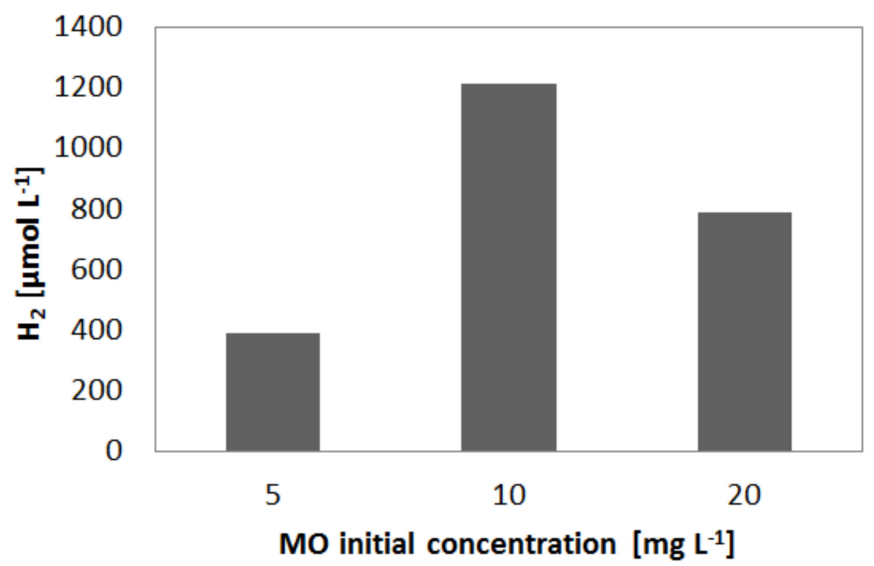

Figure 7. Effect of MO initial concentration on $\mathrm{H}_{2}$ production after $4 \mathrm{~h}$ of UV irradiation time.

It is observed that the addition of a small amount of dye (from 5 to $10 \mathrm{mg} \mathrm{L}^{-1}$ ) results in significantly enhanced $\mathrm{H}_{2}$ production (from 387 to $1216 \mu \mathrm{mol} \mathrm{L}^{-1}$ ) after $4 \mathrm{~h}$ of $\mathrm{UV}$ irradiation. Further increase of MO initial concentration up to $20 \mathrm{mg} \mathrm{L}^{-1}$ does not result in the enhancement of hydrogen production (equal to $\left.790 \mu \mathrm{mol} \mathrm{L}^{-1}\right)$, at least during the irradiation time period of the experiment $(4 \mathrm{~h})$, indicating that longer irradiation times are probably necessary for this case [5].

\section{Materials and Methods}

\subsection{Photocatalysts Preparation and Characterization}

Ru-modified $\mathrm{ZnO}$ photocatalysts were prepared by a precipitation method. An undoped $\mathrm{ZnO}$ photocatalyst was prepared using $5 \mathrm{~g}$ of zinc acetate dihydrate $\mathrm{ZnC}_{4} \mathrm{H}_{6} \mathrm{O}_{4}$ (Sigma Aldrich, 99\%) as precursor salt, dissolved in $50 \mathrm{~mL}$ of distilled water. A NaOH (Sigma Aldrich, 99\%) aqueous solution (obtained dissolving $2 \mathrm{~g}$ of $\mathrm{NaOH}$ in $25 \mathrm{~mL}$ of distilled water) was slowly added in order to obtain a precipitate. The obtained precipitate compounds were centrifuged, washed with distilled water, and calcined at a temperature equal to $600^{\circ} \mathrm{C}$ for $2 \mathrm{~h}$. Beforehand, in the case of Ru-modified $\mathrm{ZnO}$, different amounts of $\mathrm{RuCl}_{3}$ (Sigma Aldrich, 99\%) (Table 2) were added to the solution of $\mathrm{ZnC}_{4} \mathrm{H}_{6} \mathrm{O}_{4}$ to cause precipitation by the addition of $\mathrm{NaOH}$. The obtained precipitate was centrifuged, washed, 
and calcined at $600{ }^{\circ} \mathrm{C}$ for $2 \mathrm{~h}$. The Ru nominal amount is expressed as a molar percentage and it was calculated through Equation (1).

$$
\% \operatorname{mol} \mathrm{Ru}=\frac{n R u}{n R u+n \mathrm{Zn}} \times 100,
$$

where $\mathrm{n} \mathrm{Ru}$ is the number of moles of $\mathrm{RuCl}_{3}$ used in the synthesis and $\mathrm{n} \mathrm{Zn}$ is the number of moles of $\mathrm{ZnC}_{4} \mathrm{H}_{6} \mathrm{O}_{4}$ used in the synthesis. The prepared photocatalysts were characterized with several techniques. In particular, the Raman spectra of the samples were realized with a Dispersive MicroRaman system (Invia, Renishaw, England), equipped with $514 \mathrm{~nm}$ laser, in the range $100-2000 \mathrm{~cm}^{-1}$ Raman shift. Total Ru content of the samples was evaluated by X-ray fluorescence spectrometry (XRF) in a thermos Fischer ARL QUANT'X EDXRF spectrometer (Italy) equipped with a rhodium standard tube as the source of the radiation and with a Si-Li drifted crystal detector. XRD analysis was carried out to evaluate the crystal phases of the prepared photocatalysts by a Brucker D8 diffractometer, with a scan rate equal to $0.05 \%$ second (analysis range in the range 20-80 degrees). UV-vis reflectance spectra (UV-vis DRS) of powder catalysts were measured by a Perkin Elmer spectrometer (Italy) Lambda 35 using a reflectance spectroscopy accessory (Labsphere Inc., North Sutton, NH, United States of America). The photocatalysts band gap was determined from Kubelka-Munk function $\mathrm{F}(\mathrm{R} \infty)$ by plotting $[\mathrm{F}(\mathrm{R} \infty) \times \mathrm{h} v]^{2}$ vs. $\mathrm{h} v$. The specific surface areas (SSA) of the photocatalysts were evaluated through Brunauer-Emmett-Teller (B.E.T.) method by $\mathrm{N}_{2}$ adsorption at $-196^{\circ} \mathrm{C}$ with a Costech Sorptometer 1042 after a pretreatment at $150{ }^{\circ} \mathrm{C}$ for $1 \mathrm{~h}$ in a He flow.

\subsection{Photocatalytic Experiments}

The photocatalytic experiments were performed with a Pyrex reactor with a cylindrical configuration (ID $=2.5 \mathrm{~cm}$ ) equipped with a $\mathrm{N}_{2}$ distributor device $\left(\mathrm{Q}=0.125 \mathrm{NL} \mathrm{min}^{-1}\right)$. Irradiation was provided by four UV lamps (Philips, the nominal power was $8 \mathrm{~W}$ and the main peak of emission was $365 \mathrm{~nm}$ ) positioned around the external surface of the reactor at an equal distance from it (about $0.5 \mathrm{~cm}$ ) in order to uniformly irradiate the volume of the suspension. During the tests a specific amount of catalyst was suspended in $80 \mathrm{~mL}$ of an aqueous solution with methyl orange azo dye (MO) at $10 \mathrm{mg} \mathrm{L}^{-1}$ initial concentration ( $\mathrm{pH}=6.3$ ). Different catalyst dosages $\left(0.75,1.5\right.$, and $3 \mathrm{~g} \mathrm{~L}^{-1}$ ) were tested. The solution to be treated is continuously mixed by a peristaltic pump. The photocatalytic experiment is characterized by a first dark phase, necessary to reach the adsorption and desorption equilibrium of the MO on the catalyst surface, and by a second phase lasting 4 hours in the presence of UV light. The analysis of the gaseous phase from the photoreactor (city, State Abbr. (if has), country) was realized by continuous $\mathrm{H}_{2}$ analysers (ABB Advance Optima). About $2 \mathrm{~mL}$ of the aqueous sample was taken from the photoreactor at different times and centrifuged in order to remove photocatalyst particles before the analyses. The MO concentration was measured by a spectrophotometric method at $\lambda=462 \mathrm{~nm}$ (Perkin Elmer spectrophotometer, Italy).

\section{Conclusions}

The results of this work demonstrate the effectiveness of the Ru-modified $\mathrm{ZnO}$ photocatalyst in the simultaneous degradation and valorization of organic contaminants, such as Methyl Orange azo dye, present in aqueous solutions. Undoped and Ru-modified $\mathrm{ZnO}$ photocatalysts, with different $\mathrm{Ru}$ content, were successfully synthesized by a simple precipitation method. XRD and Raman analysis showed the presence of the characteristic $\mathrm{ZnO}$ signals, while from UV-vis DRS results it was evidenced that the doping of $\mathrm{ZnO}$ with Ru enhances the intensity of the light absorption in the UV region, but has no significant effect on the band gap value. Moreover, a correlation between the amount of adsorbed dye on the catalyst surface and the hydrogen production during heterogeneous photocatalysis was observed. The optimal Ru content was equal to $0.25 \mathrm{~mol} \%$ and from the photocatalytic results the obtained hydrogen production was equal to $1216 \mu \mathrm{mol} \mathrm{L}^{-1}$ after $4 \mathrm{~h}$ of UV irradiation time. This was higher than that obtained with undoped $\mathrm{ZnO}\left(767 \mu \mathrm{mol} \mathrm{L}^{-1}\right)$. This result was very interesting since it 
showed the possibility of using the photocatalytic process not only for the degradation of azo dyes present in wastewater, but also the possibility of converting these organic substances into high added value compounds (such as $\mathrm{H}_{2}$ ).

Author Contributions: G.I. performed the experiments and wrote the manuscript. V.V. provided the concept and experimental design of the study and reviewed the paper prior to submission. Both the authors discussed the results, analyzed the data, and commented on the manuscript.

Funding: This research received no external funding.

Acknowledgments: The authors wish to thank Immacolata Sansone for the support in the photocatalytic tests.

Conflicts of Interest: The authors declare no conflict of interest.

\section{References}

1. Liao, C.-H.; Huang, C.-W.; Wu, J. Hydrogen production from semiconductor-based photocatalysis via water splitting. Catalysts 2012, 2, 490-516. [CrossRef]

2. Iervolino, G.; Vaiano, V.; Sannino, D.; Rizzo, L.; Ciambelli, P. Photocatalytic conversion of glucose to $\mathrm{H}_{2}$ over $\mathrm{LaFeO}_{3}$ perovskite nanoparticles. Chem. Eng. Trans. 2016, 47, 283-288.

3. Christoforidis, K.C.; Fornasiero, P. Photocatalytic hydrogen production: A rift into the future energy supply. ChemCatChem 2017, 9, 1523-1544. [CrossRef]

4. Iervolino, G.; Vaiano, V.; Sannino, D.; Rizzo, L.; Palma, V. Enhanced photocatalytic hydrogen production from glucose aqueous matrices on Ru-doped $\mathrm{LaFeO}_{3}$. Appl. Catal. B Environ. 2017, 207, 182-194. [CrossRef]

5. Patsoura, A.; Kondarides, D.I; Verykios, X.E. Enhancement of photoinduced hydrogen production from irradiated $\mathrm{Pt} / \mathrm{TiO}_{2}$ suspensions with simultaneous degradation of azo-dyes. Appl. Catal. B Environ. 2006, 64, 171-179. [CrossRef]

6. Kim, J.; Park, Y.; Park, H. Solar hydrogen production coupled with the degradation of a dye pollutant using $\mathrm{TiO}_{2}$ modified with platinum and nafion. Int. J. Photoenergy 2014, 2014, 324859. [CrossRef]

7. Gupta, V. Application of low-cost adsorbents for dye removal—A review. J. Environ. Manag. 2009, 90, 2313-2342. [CrossRef]

8. Crini, G. Non-conventional low-cost adsorbents for dye removal: A review. Bioresour. Technol. 2006, 97, 1061-1085. [CrossRef]

9. Vaiano, V.; Iervolino, G. Facile method to immobilize $\mathrm{ZnO}$ particles on glass spheres for the photocatalytic treatment of tannery wastewater. J. Colloid Interface Sci. 2018, 518, 192-199. [CrossRef]

10. Somasundaram, S.; Veerakumar, P.; Lin, K.C.; Kumaravel, V. Application of nanocomposites for photocatalytic removal of dye contaminants. Photocatal. Funct. Mater. Environ. Remediat. 2019, 131-161. [CrossRef]

11. Bouras, H.D.; Isik, Z.; Arikan, E.B.; Bouras, N.; Chergui, A.; Yatmaz, H.C.; Dizge, N. Photocatalytic oxidation of azo dye solutions by impregnation of $\mathrm{ZnO}$ on fungi. Biochem. Eng. J. 2019, 146, 150-159. [CrossRef]

12. Zuorro, A.; Lavecchia, R.; Monaco, M.M.; Iervolino, G.; Vaiano, V. Photocatalytic degradation of azo dye reactive violet 5 on Fe-doped titania catalysts under visible light irradiation. Catalysts 2019, 9, 645. [CrossRef]

13. Kim, J; Monllor-Satoca, D.; Choi, W. Simultaneous production of hydrogen with the degradation of organic pollutants using $\mathrm{TiO}_{2}$ photocatalyst modified with dual surface components. Energy Environ. Sci. 2012, 5, 7647-7656. [CrossRef]

14. He, Y.; Sutton, N.B.; Rijnaarts, H.H.; Langenhoff, A.A. Degradation of pharmaceuticals in wastewater using immobilized $\mathrm{TiO}_{2}$ photocatalysis under simulated solar irradiation. Appl. Catal. B Environ. 2016, 182, 132-141. [CrossRef]

15. Bahruji, H.; Bowker, M.; Davies, P.R.; Pedrono, F. New insights into the mechanism of photocatalytic reforming on $\mathrm{Pd} / \mathrm{TiO}_{2}$. Appl. Catal. B Environ. 2011, 107, 205-209. [CrossRef]

16. Chu, K.H.; Ye, L.; Wang, W.; Wu, D.; Chan, D.K.L.; Zeng, C.; Yip, H.Y.; Jimmy, C.Y.; Wong, P.K. Enhanced photocatalytic hydrogen production from aqueous sulfide/sulfite solution by $\mathrm{ZnO}_{0.6} \mathrm{~S}_{0.4}$ with simultaneous dye degradation under visible-light irradiation. Chemosphere 2017, 183, 219-228. [CrossRef]

17. Wang, J; Zhang, P.; Li, X.; Zhu, J.; Li, H. Synchronical pollutant degradation and $\mathrm{H}_{2}$ production on a $\mathrm{Ti}^{3+}$-doped $\mathrm{TiO}_{2}$ visible photocatalyst with dominant (0 0 1) facets. Appl. Catal. B Environ. 2013, 134, 198-204. [CrossRef]

18. Romão, J.; Salata, R.; Park, S.-Y.; Mul, G. Photocatalytic methanol assisted production of hydrogen with simultaneous degradation of methyl orange. Appl. Catal. A Gen. 2016, 518, 206-212. [CrossRef] 
19. Badawy, M.I.; Ali, M.E.; Ghaly, M.Y.; El-Missiry, M.A. Mesoporous simonkolleite-- $\mathrm{TiO}_{2}$ nanostructured composite for simultaneous photocatalytic hydrogen production and dye decontamination. Process Saf. Environ. Prot. 2015, 94, 11-17. [CrossRef]

20. Vaiano, V.; Jaramillo-Paez, C.A.; Matarangolo, M.; Navío, J.A.; del Carmen Hidalgo, M. UV and visible-light driven photocatalytic removal of caffeine using $\mathrm{ZnO}$ modified with different noble metals (Pt, Ag and $\mathrm{Au}$ ). Mater. Res. Bull. 2019, 112, 251-260. [CrossRef]

21. Tijare, S.N.; Joshi, M.V.; Padole, P.S.; Mangrulkar, P.A.; Rayalu, S.S.; Labhsetwar, N.K. Photocatalytic hydrogen generation through water splitting on nano-crystalline $\mathrm{LaFeO}_{3}$ perovskite. Int. J. Hydrogen Energy 2012, 37, 10451-10456. [CrossRef]

22. Xie, M.-Y.; Su, K.-Y.; Peng, X.-Y.; Wu, R.-J.; Chavali, M.; Chang, W.-C. Hydrogen production by photocatalytic water-splitting on Pt-doped $\mathrm{TiO}_{2}-\mathrm{ZnO}$ under visible light. J. Taiwan Inst. Chem. Eng. 2017, 70, 161-167. [CrossRef]

23. Chen, X.; Lou, Y.; Dayal, S.; Qiu, X.; Krolicki, R.; Burda, C.; Zhao, C.; Becker, J. Doped semiconductor nanomaterials. J. Nanosci. Nanotechnol. 2005, 5, 1408-1420. [CrossRef] [PubMed]

24. Ibhadon, A.; Greenway, G.; Yue, Y. Photocatalytic activity of surface modified $\mathrm{TiO}_{2} / \mathrm{RuO}_{2} / \mathrm{SiO}_{2}$ nanoparticles for azo-dye degradation. Catal. Commun. 2008, 9, 153-157. [CrossRef]

25. Aranganayagam, K.; Senthilkumaar, S.; Ganapathi Subramaniam, N.; Kang, T.W. Ruthenium doped ZnO semiconductor: Synthesis, characterization and photodegradation of azo dye. Int. J. Nanosci. 2013, 12, 1350009. [CrossRef]

26. Yayapao, O.; Thongtem, T.; Phuruangrat, A.; Thongtem, S. Synthesis and characterization of highly efficient $\mathrm{Gd}$ doped $\mathrm{ZnO}$ photocatalyst irradiated with ultraviolet and visible radiations. Mater. Sci. Semicond. Process. 2015, 39, 786-792. [CrossRef]

27. Manríquez, M.E.; Noreña, L.E.; Wang, J.A.; Chen, L.; Salmones, J.; González-García, J.; Reza, C.; Tzompantzi, F.; Hernández Cortez, J.G.; Ye, L. One-pot synthesis of Ru-doped ZnO oxides for photodegradation of 4-chlorophenol. Int. J. Photoenergy 2018, 2018, 7605306. [CrossRef]

28. Reksten, A.H.; Russell, A.E.; Richardson, P.W.; Thompson, S.J.; Mathisen, K.; Seland, F.; Sunde, S. Strategies for the analysis of the elemental metal fraction of Ir and Ru oxides via XRD, XANES, and EXAFS. Phys. Chem. Chem. Phys. 2019, 21, 12217-12230. [CrossRef]

29. Wojnarowicz, J.; Mukhovskyi, R.; Pietrzykowska, E.; Kusnieruk, S.; Mizeracki, J.; Lojkowski, W. Microwave solvothermal synthesis and characterization of manganese-doped $\mathrm{ZnO}$ nanoparticles. Beilstein J. Nanotechnol. 2016, 7, 721-732. [CrossRef]

30. Zhang, Q.; Liu, J.-K.; Wang, J.-D.; Luo, H.-X.; Lu, Y.; Yang, X.-H. Atmospheric self-induction synthesis and enhanced visible light photocatalytic performance of $\mathrm{Fe}^{3+}$ doped $\mathrm{Ag}-\mathrm{ZnO}$ mesocrystals. Ind. Eng. Chem. Res. 2014, 53, 13236-13246. [CrossRef]

31. Janotti, A.; Van de Walle, C.G. Fundamentals of zinc oxide as a semiconductor. Rep. Progress Phys. 2009, 72, 126501. [CrossRef]

32. Ilanchezhiyan, P.; Kumar, G.M.; Subramanian, M.; Jayavel, R. Effect of Pr doping on the structural and optical properties of ZnO nanorods. Mater. Sci. Eng. B 2010, 175, 238-242. [CrossRef]

33. Bloh, J.Z.; Dillert, R.; Bahnemann, D.W. Ruthenium-modified zinc oxide, a highly active vis-photocatalyst: The nature and reactivity of photoactive centres. Phys. Chem. Chem. Phys. 2014, 16, 5833-5845. [CrossRef] [PubMed]

34. Sakthivel, S.; Shankar, M.; Palanichamy, M.; Arabindoo, B.; Bahnemann, D.; Murugesan, V. Enhancement of photocatalytic activity by metal deposition: Characterisation and photonic efficiency of $\mathrm{Pt}, \mathrm{Au}$ and $\mathrm{Pd}$ deposited on $\mathrm{TiO}_{2}$ catalyst. Water Res. 2004, 38, 3001-3008. [CrossRef] [PubMed]

35. Chakrabarti, S.; Dutta, B.K. Photocatalytic degradation of model textile dyes in wastewater using $\mathrm{ZnO}$ as semiconductor catalyst. J. Hazard. Mater. 2004, 112, 269-278. [CrossRef]

36. Mohagheghian, A.; Karimi, S.-A.; Yang, J.-K.; Shirzad-Siboni, M. Photocatalytic degradation of a textile dye by illuminated tungsten oxide nanopowder. J. Adv. Oxid. Technol. 2015, 18, 61-68. [CrossRef]

(C) 2019 by the authors. Licensee MDPI, Basel, Switzerland. This article is an open access article distributed under the terms and conditions of the Creative Commons Attribution (CC BY) license (http://creativecommons.org/licenses/by/4.0/). 